SAUCEDA, Brenda; GORGÓN, Gabriel. "Justicia restaurativa, una herramienta de paz en la resolución de conflictos comunitarios. Caso Nuevo León”.

Polít. crim. Vol. 13, № 25 (Julio 2018) Art. 14, pp. 548 - 571

[http://www.politicacriminal.cl/Vol_13/n_25/Vol13N25A14.pdf]

\title{
Justicia restaurativa, una herramienta de paz en la resolución de conflictos comunitarios. Caso Nuevo León.
}

\author{
Restorative justice, a tool of peace in the resolution of community conflicts. \\ Nuevo León case. \\ Dr. Gabriel de Jesús Gorjón Gómez \\ Doctor en Derecho por la Universidad Autónoma de Nuevo León; \\ Profesor de Tiempo Completo de la Universidad Autónoma de Nuevo León. \\ Código ORCID: http://orcid.org/0000-0001-5033-9377 \\ ggorjon@ hotmail.com \\ Dra. Brenda Judith Sauceda Villeda \\ Doctora en Métodos Alternos de Solución de Conflictos; \\ Docente de la Universidad Autónoma de Nuevo León. \\ Código ORCID: http://orcid.org/0000-0003-3614-7875 \\ judith_sauceda@hotmail.com
}

Resumen. La presente investigación aborda el beneficio del uso de la justicia restaurativa en el ámbito comunitario, al margen de la legislación actual y tomando como base que los ciudadanos tienen derechos y obligaciones dentro de su comunidad para vivir de manera armónica, y tienen responsabilidad con los ofensores y víctimas de delitos, quienes también son vecinos y forman parte del sistema social. Asimismo, se expone entre otras cosas, los objetivos de la justicia restaurativa, su diferencia con la mediación comunitaria, la reparación del daño con efectos restaurativos, y la necesidad de implementarse programas de justicia restaurativa en el contexto comunitario del Estado de Nuevo León.

Palabras clave: Justicia restaurativa, comunidad, conflicto comunitario, mediación comunitaria.

\begin{abstract}
The present investigation deals with the benefit of the use of restorative justice at the community level, outside from the current legislation and on the basis that citizens have rights and obligations within their community to live harmoniously, and have responsibility to offenders and victims of crimes, who are also neighbors and part of the social system. It also exhibits, among other things, the objectives of restorative justice, its difference with community mediation, the repair of damage with restorative effects, and the need to implement restorative justice programs in the community context of the state of Nuevo León.
\end{abstract}

Keywords: restorative justice, community, community conflict, community mediation.

\section{Introducción}

El contexto social urbano presenta una gama de conflictos entre vecinos, que pueden ser resueltos con apoyo de las instancias de gobierno y de la sociedad civil. Es necesario considerar que los vecinos son personas que generalmente interactúan a causa de la cercanía de su vivienda. La 
cotidianeidad genera cambios en las relaciones interpersonales, estos cambios se presentan por la convivencia entre ellos, sin embargo, existen algunos factores que crean prejuicios que influyen para que los ciudadanos brinden o no la oportunidad de integración social a algunas personas, como es el caso de quienes han cometido delitos, o han sido imputados, enjuiciados o presidiarios.

A la luz de la existencia de normas jurídicas, tenemos que el rol de vecino implica la dualidad de sujeto activo de derechos y a su vez sujeto pasivo sobre quien recaen obligaciones como ciudadano que forma parte de una comunidad. Existen conflictos que trascienden de tal manera que afectan las relaciones entre vecinos, las cuales comúnmente inician como relaciones sociales en donde predomina la identidad social como vecino que forma parte de determinada comunidad, en ocasiones dichas relaciones pasan al ámbito individual creándose vínculos personales y manifestaciones de confianza entre los vecinos; en ambos casos es importante la implementación de estrategias que apoyen el desarrollo de habilidades para resolver conflictos presentes o futuros, fomentando la cultura de paz.

\section{El conflicto comunitario}

El conflicto está compuesto por una serie de etapas o por una o varias situaciones en las que participan individuos o colectividades, y que a causa de sus intereses, necesidades, ideas o factores se encuentran con desavenencias que afectan la convivencia ciudadana y las relaciones interpersonales entre los vecinos.

Cuando los conflictos acontecen en la comunidad, es decir, al existir una desavenencia entre vecinos que no fue atendida oportuna y debidamente, se generan sentimientos negativos que atentan contra la relación vecinal, teniendo como efectos el individualismo, alejamiento del grupo vecinal, proliferación de discrepancias sin motivo aparente, discusiones, rumores, en algunos casos hasta llegar al desencadenamiento de hechos delictuosos desde agresiones verbales o físicas, ofensas, daño en propiedad ajena, hasta lesiones leves, graves u homicidio.

La particularidad de los conflictos comunitarios consiste en que la relación vecinal es diferente a otros tipos de relaciones, ya que el rol de vecino no es de un amigo o familiar, sino más bien, se trata de una persona cuya característica común es la proximidad física con otra u otras personas ${ }^{1}$, con quienes la relación puede ser o no armónica. Es por ello que sus conflictos deben ser tratados de forma distinta a los de otra naturaleza, en virtud de que la proximidad física es en razón a la adjudicación, propiedad o posesión de un bien inmueble, mismo que regularmente se destina a casa habitación o negocio.

\section{Aproximación a la solución del conflicto comunitario.}

Para la solución del conflicto no basta remitirnos a la consecuencia jurídica por la falta de cumplimiento de la norma, donde si A es acreedor de un derecho, entonces B debe cumplir una obligación de dar, hacer o no hacer ${ }^{2}$, si se concreta el cumplimiento de la obligación (+), lo consideramos como $\mathrm{AB}$ (porque la voluntad de las partes se cohesiona en el cumplimiento de lo pactado); si B no cumple (-), la única forma de solucionar el problema en el sistema tradicional,

\footnotetext{
${ }^{1}$ KELLER, Suzanne, El vecindario urbano: Una perspectiva sociológica, $2^{\mathrm{a}}$ edición, Madrid (España): Editorial Siglo XXI, 1979, p. 29.

2 Ver Artículo 1824 del Código Civil Federal.
} 
SAUCEDA, Brenda; GORGÓN, Gabriel. “Justicia restaurativa, una herramienta de paz en la resolución de conflictos comunitarios. Caso Nuevo León”.

había sido a través de la coacción, la cual definimos para el desarrollo de este silogismo como C, en representación de cualquier otro factor punitivo ${ }^{3}$.

En materia de justicia restaurativa el camino es distinto: el elemento más importante es la voluntad de las partes para resolver un conflicto y alcanzar el perdón en caso de que proceda, las opciones pueden ser responsabilidad (D), restauración (E) y reintegración y/o reinserción social (F), donde si A es acreedor de un derecho, entonces B debe cumplir una obligación de dar, hacer o no hacer, si se concreta el cumplimiento de la obligación (+), lo consideramos como D, E o F 4 .

En este orden de ideas, se requiere la implementación de prácticas restaurativas que permitan un cambio de paradigma en la solución de conflictos, que sea capaz de generar o regenerar confianza e inclusive lazos sociales y afectivos entre los miembros de la comunidad, transformando las relaciones interpersonales en base a estrategias que generan el diálogo pacífico y participativo, y no únicamente buscar la solución de un conflicto sustentado en la lógica jurídica basada en las disposiciones vigentes.

Eduard Vinyamata Camp ${ }^{5}$ considera importante el medio y la voluntariedad de las partes para ampliar las opciones de solución a los conflictos, tomando como base la idea de Einstein referente a que un problema sin solución es un problema mal planteado y la afirmación de que "los problemas no pueden resolverse con los mismos medios con los cuales se han generado" 6 .

Una vez que tenemos a nuestro alcance los elementos mencionados, es pertinente observar y analizar el conflicto comunitario, ya que debemos tomar en cuenta al seleccionar el método, técnica o práctica restaurativa, las causas de los conflictos, porque de acuerdo a Vinyamata "una comprensión observada desde una actitud que no prejuzgue y desde el conocimiento que las causas de los conflictos pueden tener orígenes diversos. Pueden tener causas estructurales, de formas de vivir, de pensar, de concebir la vida de una manera u otra, pueden tener causas relacionadas con la salud física o psíquica, el entorno social o las capacidades comunicativas"”.

Para llevar a cabo las prácticas restaurativas también es necesario que las instancias gubernamentales motiven la participación de los ciudadanos para formar agentes de cambio que colaboren en la transformación de las relaciones vecinales mediante el uso de los métodos alternos de solución de conflictos como la mediación, y a su vez, desarrollando prácticas restaurativas que motiven la interacción pacífica entre los miembros de la comunidad, lo que finalmente impacta de forma positiva en los indicadores de cohesión social ${ }^{8}$.

\footnotetext{
${ }^{3}$ Es decir, A más B es igual a AB, si B no cumple con la obligación, entonces debe ser sancionado A menos B es igual a C.

${ }^{4}$ Con la justicia restaurativa existen múltiples alternativas para solucionar el conflicto: A + B = Puede ser D, E o F.

${ }^{5}$ VINYAMATA CAMP, Eduard, "Conflictología", Revista de Paz y Conflictos, vol. 8, no 1 (2015), pp. 9-24, p. 17, en: http://revistaseug.ugr.es/index.php/revpaz/article/view/2717/3176

${ }^{6}$ VINYAMATA CAMP, "Conflictología”, cit. nota núm. 3, p. 17.

${ }^{7}$ VINYAMATA CAMP, "Conflictología”, cit. nota núm. 3, p. 17.

${ }^{8}$ Los indicadores de cohesión social a los que nos referimos son la participación ciudadana, la confianza entre vecinos y el sentido de pertenencia. FUNDACIÓN HOGARES, IAP., "Bases para la construcción de un índice de cohesión social vecinal", (2015), pp. 1-31, p. 10, en:

http://www.fundacionhogares.org/documentos/indice\%20de\%20coesion\%20social.pdf
} 
Polít. crim. Vol. 13, No 25 (Julio 2018) Art. 14, pp. 548 -

[http://www.politicacriminal.cl/Vol_13/n_25/Vol13N25A14.pdf]

Fundación Este País y Banamex realizaron un estudio empírico comprendiendo la relación entre bienestar subjetivo, cohesión y relaciones sociales en México y sus entidades federativas, en donde resultó que a mayor confianza interpersonal existe también una mayor satisfacción de vida; también se observa que a mayor presencia de trabajo voluntario se aprecia mayor satisfacción de vida entre la población ${ }^{9}$ y que los vínculos y relaciones sociales son muy bajos en las comunidades estudiadas ${ }^{10}$.

La cohesión social ha sido estudiada a través de indicadores que permiten su medición en el ámbito vecinal. Fundación Hogares ha implementado un modelo de Índice de Cohesión Social Vecinal definiendo a este fenómeno como un atributo descriptivo de una comunidad o grupo social que se materializa en el conjunto de vínculos e interacciones que se desarrollan entre los miembros de la misma, como producto de sus actitudes y valores individuales tales como la confianza, las redes personales de apoyo o el sentido de pertenencia. ${ }^{11}$

En base a dichos estudios consideramos que para promover la cohesión social se requiere la participación de los miembros de la comunidad en la solución de los conflictos comunitarios lo que permite mayor satisfacción, relaciones interpersonales sanas, bienestar subjetivo, y fortalece la integración social y propicia identidades sociales. Los miembros de la comunidad requieren de un facilitador que propicie una dinámica funcional en favor del desarrollo de habilidades y técnicas de comunicación que ayuden al vecino a resolver los conflictos comunitarios, ya sea como parte en un conflicto determinado o como actor en el proceso de paz para lograr un beneficio colectivo.

De esta manera, la corresponsabilidad y la participación de los miembros de la comunidad son las partes medulares para culminar el proceso de culturización de la paz, evitando el abuso hacia los vecinos que cuenten con mayor disponibilidad de tiempo para participar de manera honorífica en la solución de conflictos. La tarea de concientizar a la población no es sencilla, implica un esfuerzo por cambiar hacia un entorno plural para solucionar los conflictos del día a día.

Ahora bien, los acuerdos de la comunidad no son perfectos o imperfectos, sólo deben existir acuerdos creados en base a las necesidades e intereses de los intervinientes en el conflicto, para lo cual, además de los principios de la mediación, se requiere la reparación del daño, material o inmaterial, tangible o intangible. Por lo que más allá de un procedimiento que concluya con un acuerdo de reparación y al entendimiento del deber ser, es necesario un cambio de paradigma para alcanzar la reconciliación y en su caso al perdón, desdibujando sentimientos de odio o venganza entre los vecinos, ya sean ofensores, víctimas u ofendidos, evitando una nueva escalada de

9 CASTELLANOS CERECEDA, Roberto, "Comprendiendo la relación entre bienestar subjetivo, cohesión y relaciones sociales. Una aproximación al caso de México y sus entidades federativas”, Circunstancia, Año XI, No. 31 (2013), p.p. 1-19, p. 8 y 10, en:

http://www.ortegaygasset.edu/admin/descargas/contenidos/Roberto_Castellanos_Cereceda.pdf

${ }^{10}$ Los conjuntos habitacionales estudiados fueron los siguientes: San Diego Linares en Toluca, Estado de México; Granjas del Marqués popularmente conocida como Luis Donaldo Colosio en Acapulco, Guerrero; Ciudad Olmeca en Coatzacoalcos, Veracruz; y, Cañadas del Florido en Tijuana, Baja California.

${ }^{11}$ FUNDACIÓN HOGARES, IAP., "Bases”, cit. nota núm. 1, p. 10. 
SAUCEDA, Brenda; GORGÓN, Gabriel. "Justicia restaurativa, una herramienta de paz en la resolución de conflictos comunitarios. Caso Nuevo León”.

conflictos que, en ocasiones, puede tornarse en una negativa espiral de situaciones adversas cuyas repercusiones pueden presentarse en una escalada mayor a la que dio origen al conflicto inicial.

La violencia generada por comportamientos desmesurados actualmente ha afectado, tanto nuestro ámbito privado y colectivo, hasta convertirse en una forma de vida cotidiana, por lo que se debe hacer un esfuerzo para percibir todas sus dimensiones y, a partir de ahí, intentar reducir la violencia. La evolución de comportamientos violentos está condicionada al entorno social, económico, político y cultural donde nos encontramos ${ }^{12}$.

Como todo conflicto tiene sus particularidades, así de particular será la búsqueda de la solución; para iniciar esa búsqueda se requiere identificar si el conflicto comunitario a tratar puede ser solucionado mediante algún método alterno de solución de conflictos como la mediación, conciliación o a través de las prácticas restaurativas, de acuerdo a las condiciones y características del conflicto.

Es así como no es conveniente representar a las partes con la dualidad A y B, en donde C es la respuesta inequívoca a la solución del conflicto comunitario basado en un silogismo jurídico con opciones predeterminadas, sino que, más bien, la solución debe basarse en todos los elementos que resulten de la voluntad, la escucha activa y el diálogo pacífico. Por ello, en el presente trabajo se tienen algunas consideraciones sobre la viabilidad para implementar prácticas restaurativas en los conflictos vecinales en la urbe Neolonesa.

\section{Justicia social.}

Hartnett explica que la justicia implica la promoción del acceso y la equidad para asegurar la plena participación en la vida social, especialmente para aquellos que han sido sistemáticamente excluidos sobre la base de su etnia, edad, género, habilidad física o mental, educación, orientación sexual, situación socioeconómica u otras características del grupo de pertenencia. De esta forma, la justicia social se asienta sobre la convicción de que todos los seres humanos tienen derecho a un trato equitativo, a un apoyo para alcanzar sus derechos humanos y a una distribución justa de los recursos sociales ${ }^{13}$.

La justicia social, al igual que la justicia restaurativa, tiene un impacto de índole social, con perspectiva de derechos humanos y sirve para proteger a los grupos vulnerables de la sociedad, que son aquellas personas que están en una situación de riesgo por encontrarse en una condición de desventaja social que los limita al acceso a un sano desarrollo integral.

Los grupos vulnerables más frecuentemente reconocidos como tales por sus características de desventaja o desigualdad social son: las niñas, los niños, los adolescentes, las mujeres, adultos mayores, personas con discapacidad o enfermedad mental e indígenas. No obstante, estimamos que

\footnotetext{
12 JIMÉNEZ-BAUTISTA, Francisco, "Conocer para comprender la violencia: origen, causas y realidad", Revista Convergencia, Revista de Ciencias Sociales, Volumen 19, No. 58, (2012), p.p. 13-52, p. 16 y 17 , en: http://www.redalyc.org/pdf/105/10520680001.pdf

${ }^{13}$ MURILlO TORRECILLA, F. J., \& HERNÁNDEZ CASTILLA, R., "Hacia un Concepto de Justicia Social", REICE. Revista Iberoamericana sobre Calidad, Eficacia y Cambio en Educación, Volumen 9, No. 4 (2011), p.p. 723, p.18, en: https://www.uam.es/personal_pdi/stmaria/jmurillo/arts/reice/vol9num4_art1.pdf.
} 
Polít. crim. Vol. 13, No 25 (Julio 2018) Art. 14, pp. 548 -

[http://www.politicacriminal.cl/Vol_13/n_25/Vol13N25A14.pdf]

cualquier persona puede tener la condición de vulnerable, por las circunstancias en que se encuentre o la falta de oportunidad de desarrollo, por lo que consideramos también como grupos vulnerables a quienes padezcan alguna adicción, a los extranjeros y a los expresidiarios.

Analizar cuáles son las características de vulnerabilidad o desventaja social, permite las providencias necesarias para llevar a cabo prácticas restaurativas de forma integral, como por ejemplo nombrar a quien tenga la patria potestad, guarda o custodia, representante legal, traductor, agente intercultural, e inclusive instancias gubernamentales o de la sociedad civil que protejan los derechos de dichos gremios en lo particular.

\subsection{Perspectiva de derechos humanos en la justicia social.}

Los derechos para garantizar la justicia social son protegidos a través del Pacto Internacional de Derechos Económicos, Sociales y Culturales de 1966, en su artículo 2.1, señala que los Estados partes quedan comprometidos a adoptar las medidas, tanto por separado o a través de la cooperación internacional, hasta el máximo de los recursos de que disponga, para lograr progresivamente la plena efectividad de los derechos reconocidos en el Pacto.

La Convención Americana de Derechos Humanos otorga bases jurídicas para que sus órganos defensores de derechos humanos conozcan de violaciones a esos derechos. El artículo 26 de dicha Convención señala como compromiso de desarrollo progresivo adoptar providencias, tanto a nivel interno como mediante la cooperación internacional, especialmente económica y técnica, para lograr progresivamente la plena efectividad de los derechos que se derivan de las normas económicas, sociales y sobre educación, ciencia y cultura, contenidas en la Carta de la Organización de los Estados Americanos ${ }^{14}$.

En términos generales, los derechos humanos deben ser respetados para proteger la dignidad humana y alcanzar la justicia social y todos los ciudadanos deben ser tratados en un plano de igualdad, lo que tiene consonancia con la justicia restaurativa, ya que ésta última permite que la víctima y el ofensor puedan tener una igualdad sustantiva como intervinientes del procedimiento restaurativo, quienes cuentan con el mismo empoderamiento y oportunidad de resolver su conflicto, así como llegar a una reparación, cabiendo la posibilidad de perdonar y reconciliarse consigo mismo y los demás, respetando la dignidad de ambos, la inclusión, la no discriminación, la participación, la interculturalidad, la corresponsabilidad, el acceso a una vida libre de violencia y la accesibilidad.

Alguna normativa garante del respeto a los derechos de los grupos vulnerables citados son: Convención de las Naciones Unidas sobre los Derechos del Niño, Convención de las Naciones Unidas contra el Tráfico Ilícito de Estupefacientes y Sustancias Sicotrópicas y la Declaración de la Asamblea General de las Naciones Unidas sobre los principios rectores de la reducción de la demanda de drogas, Principios de las Naciones Unidas para la protección de los enfermos mentales y para el mejoramiento de la atención de la salud mental y Séptima Conferencia de las Naciones Unidas sobre Prevención del Delito y Tratamiento del Delincuente, entre otras normas internacionales.

${ }^{14}$ San José, Costa Rica, noviembre 1969. 
SAUCEDA, Brenda; GORGÓN, Gabriel. "Justicia restaurativa, una herramienta de paz en la resolución de conflictos comunitarios. Caso Nuevo León”.

\section{Justicia restaurativa.}

La justicia restaurativa ha sido definida como movimiento social, como un proceso, como una filosofía, como estrategia o como herramienta, y ha sido estudiada desde sus orígenes en el ámbito criminológico, por lo que nos permitiremos citar las aportaciones de algunos autores como referencia.

La justicia restaurativa surgió en la década de los años 70 como una forma de mediación entre víctimas y delincuentes y en la década de los años 90 amplió su alcance para incluir también a las comunidades de apoyo, con la participación de familiares y amigos de las víctimas y los delincuentes en procedimientos de colaboración denominados reuniones de restauración y círculos 15 .

Los principios internacionales en esta materia se derivaron de los siguientes ordenamientos ${ }^{16}$ :

1. La Declaración sobre los principios fundamentales de justicia para las víctimas del delito (1985 Asamblea General de la ONU resolución 40/34 el 29 de noviembre) que otorga a las partes acceso a los mecanismos de justicia que garanticen la reparación del daño, señalando en su artículo 7 que: “... la utilización, cuando proceda, de mecanismos oficiosos para la solución de controversias, incluidos la mediación, el arbitraje y las prácticas de justicia consuetudinaria o autóctonas, a fin de facilitar la conciliación y la reparación a favor de las víctimas".

2. Los principios básicos sobre la utilización de programas de justicia restaurativa en materia penal (Consejo Económico y Social de la ONU, 2002), determinado que el proceso restaurativo es: "Cualquier proceso en el que la víctima y el delincuente y cuando es adecuado cualquier otro individuo o miembros de la comunidad afectados por un crimen, participan en conjunto activamente en la resolución de asuntos derivados del crimen, generalmente con ayuda de un facilitador. Los procesos restaurativos pueden incluir mediación, conciliación, conferencias y círculos de sentencias".

3. La Declaración de Bangkok de 2005, originada del $11^{\circ}$ Congreso de Naciones Unidas sobre Prevención del Delito y Justicia Penal, que impulsa la elaboración de políticas, procedimientos y programas en materia de justicia restaurativa que incluyan las salidas alternas.

Según dispone el Artículo 17 de la Constitución Política de los Estados Unidos Mexicanos, el Estado deberá garantizar la administración de justicia por tribunales expeditos, con lo que se pretende evitar que ninguna persona haga justicia por sí misma, ni ejerza violencia para reclamar su derecho y accedan a dicha justicia mediante procedimientos judiciales y mecanismos de reparación del daño; el precepto en mención también faculta a los Estados para que cuenten con leyes que prevean mecanismos alternativos de solución de controversias.

${ }^{15}$ MÁRQUEZ CÁRDENAS, Álvaro E., "La doctrina social sobre la justicia restaurativa". Prolegómenos. Derechos y Valores, Volumen XII, No. 24 (2009), p.p. 59-75, p. 59, en:

http://www.redalyc.org/pdf/876/87617269005.pdf

${ }^{16}$ GORJÓN GÓMEZ, Gabriel; GORJÓN GÓMEZ, Francisco; y Otros, Comentarios a la Ley Nacional de Mecanismos Alternativos de Solución de Controversias en Materia Penal, México D.F.: Editorial Tirant lo Blanch, 2015, p. 14. 
Del precepto constitucional en cita entendemos que el legislador faculta para llevar a cabo la impartición de justicia en México a los tribunales competentes, pero además faculta a los Estados para la creación de leyes en materia de métodos alternos de solución de conflictos, por lo que es de suma importancia definir qué es la justicia restaurativa y a quién le corresponde su aplicación.

Ahora bien, la Teoría de la Impetración de la Justicia de Francisco Gorjón Gómez ${ }^{17}$, primeramente sitúa los elementos que evidencian la necesidad de la implementación de los Métodos Alternos de Solución de Conflictos (MASC), su influencia en los procesos de impartición y procuración de justicia, el tránsito de una justicia tradicional y retributiva a una justicia alternativa y restaurativa, asumiendo como uno de sus principales objetivos que los MASC sean considerados herramientas de paz y la coparticipación ciudadana en los procesos de justicia, no siendo entonces la justicia en toda la extensión de la palabra, un hecho privativo del poder judicial.

Para dicho autor, esta teoría sienta las bases sobre una ideología de ciudadanización de la justicia, explicando que la impetración de la justicia implica una intervención de las personas y de la sociedad en la solución de conflictos determinados en el proceso de búsqueda de soluciones que el sistema judicial y de procuración de justicia requieren para cumplir con sus postulados. En base a dicha teoría, podemos afirmar que los individuos y la sociedad en general pueden intervenir en los conflictos comunitarios, respetando el marco normativo vigente.

Conforme al Manual de Programas de Justicia Restaurativa de Naciones Unidas, las denominaciones utilizadas para describir a la justicia restaurativa se encuentran los de justicia comunitaria, hacer reparaciones, justicia positiva, justicia relacional, justicia reparadora y justicia restauradora ${ }^{18}$. Howard Zehr opina que la justicia restaurativa es un "proceso dirigido a involucrar, dentro de lo posible, a todos los que tengan un interés en una ofensa particular, e identificar y atender colectivamente los daños, necesidades y obligaciones derivados de dicha ofensa, con el propósito de sanar y enmendar los daños de la mejor manera posible."19

Dicho autor comenta que la justicia restaurativa está construida sobre tres elementos que conciernen a las víctimas, a los ofensores y a la comunidad: "Los daños y las necesidades asociadas a ellos; las obligaciones que conlleva este daño, así como las que le dieron origen; y la participación de todas aquellas personas que tengan un interés legítimo en la ofensa y su reparación"20.

\footnotetext{
${ }^{17}$ GORJÓN GÓMEZ, Francisco Javier. “Teoría de la Impetración de la Justicia. Por la necesaria ciudadanización de la justicia y la paz", Comunitania, Revista Internacional de Trabajo Social y Ciencias Sociales, No. 10 (2015), p. 113131, p. 115, en:

http://www.comunitania.com/numeros/numero-10/francisco-javier-gorjon-teoria-de-la-impetracion-de-la-justiciapor-la-necesaria-ciudadanizacion-de-la-justicia-y-la-paz.pdf

${ }^{18}$ ONU, Oficina de las Naciones Unidas contra la Droga y el Delito. Manual de programas de justicia restaurativa, Viena: Serie de Manuales sobre Justicia Penal, 2006, pp. 1-109, p. 6, en: https://www.unodc.org/documents/justiceand-prison-reform/Manual_sobre_programas_de_justicia_restaurativa.pdf.

${ }^{19}$ ZEHR, Howard. El pequeño libro de la justicia restaurativa. Pennsylvania: Good Books, 2007, pp. 1-96, p. 45, en: http://www.icbf.gov.co/portal/page/portal/PortalICBF/bienestar/proteccion/responsabilidad-penal/justiciarestaurativa/Howard\%20Zher\%20$\% 20$ El\%20pequen\%CC\%83o\%20Libro\%20de\%20la\%20Justicia\%20Restaurativa.pdf

${ }^{20}$ ZEHR, El pequeño libro, cit. nota núm. 2, p. 28.
} 
SAUCEDA, Brenda; GORGÓN, Gabriel. "Justicia restaurativa, una herramienta de paz en la resolución de conflictos comunitarios. Caso Nuevo León”.

Según Lederach, es necesario que las partes en conflicto descubran formas para encontrarse consigo mismas y con sus enemigos, tomando en cuenta sus necesidades y miedos, la reconciliación representa un lugar, el punto de encuentro donde se pueden aunar los intereses del pasado y del futuro ${ }^{21}$.

Por lo cual para construir la paz social se requiere del uso de prácticas restaurativas en aras de la teoría de las tres erres (R's) de Galtung, quien establece la idea de la transformación de los conflictos como medio para lograr la paz a través de tres elementos: reconstrucción (tras la violencia), reconciliación (de las partes) y resolución ${ }^{22}$.

El propio Galtung relaciona las actitudes, conducta y contradicción con tres manifestaciones de violencia: directa, cultural y estructural, vinculando la reconciliación con la necesidad de revertir las actitudes violentas, la reconstrucción con la recuperación tras la violencia directa y la resolución de las contradicciones e incompatibilidades tratando de superar la violencia estructural ${ }^{23}$.

Por otra parte, Lederach refiere que la reconciliación es un proceso implícito en la transformación de los conflictos, ayuda a los involucrados a superar sus traumas y problemas, y es una potencialidad ya que ofrece posibilidades que se construyen sobre mecanismos que comprometen a las partes en conflicto, las acercan, las ponen de frente y logran hacer que se acepten, de este modo es un espacio de verdad, misericordia, justicia y paz ${ }^{24}$.

Debemos considerar que, bajo la óptica de Galtung, la reconciliación está constituida de dos momentos 25 :

“a) El cierre, es decir, que no se regrese a las agresiones, para lo que es fundamental la conducta.

b) La curación, esto es, el proceso de rehabilitación, en el que se base el cambio de actitud."

Por lo anterior, consideramos que la justicia restaurativa es una herramienta que permite crear condiciones que favorezcan la participación de los vecinos, víctimas, ${ }^{26}$ ofensores y a la comunidad en general como grupo en la solución del conflicto, la reparación del daño y la reintegración del tejido social. La implementación de la justicia restaurativa en los conflictos vecinales, generaría que, de una manera constructiva, los vecinos reconozcan que existe un conflicto, asumirlo con responsabilidad, conocer sus derechos, ver alternativas para reparar el daño causado, pero además,

${ }^{21}$ LEDERACH, John Paul. Construyendo la paz: Reconciliación sostenible en sociedades diversas. Bilbao: Ed. Bakeaz, 1998. pp. 1-194, p. 47.

${ }^{22}$ FISAS, Vinces. Cultura de paz y gestión de conflictos. Barcelona: Ed. Icaria/Antrazyt. UNESCO, 2001, pp. 1-408, p. 231.

${ }^{23}$ FISAS, Cultura de paz y gestión de conflictos, cit. nota núm. 2, p. 49.

${ }^{24}$ LEDERACH, Construyendo la paz, cit. nota núm. 2, p. 47.

${ }^{25}$ ROMERA I. RUEDA, Raúl. Guerra, posguerra y paz: Pautas para el análisis y la intervención en contextos posbélicos o post-acuerdo, Barcelona: Editorial Icaria, 2003, pp. 1-198, p. 49.

${ }^{26}$ Para lo cual es adecuada la aplicación de los derechos de las víctimas establecidos en la Declaración sobre los Principios Fundamentales de Justicia para las Víctimas de Delito y del Abuso de Poder, emitida por la Asamblea General de la Organización de Naciones Unidas, mediante la Resolución 40/34 de fecha 29 de noviembre de 1985, así como la Ley General de Víctimas publicada en el Diario Oficial de la Federación el 9 de enero de 2013 y la Ley de Víctimas del Estado de Nuevo León publicada en el Periódico Oficial en fecha 7 de diciembre de 2013. 
Polít. crim. Vol. 13, No 25 (Julio 2018) Art. 14, pp. 548 -

[http://www.politicacriminal.cl/Vol_13/n_25/Vol13N25A14.pdf]

se puede obtener como resultado la comprensión de la situación, la reconciliación y el perdón visto como un sentimiento genuino de compasión.

En algunos casos implicaría que el procedimiento deba desarrollarse en mayor o menor tiempo, por lo cual se requiere disponibilidad de los facilitadores y de las instituciones a las que se encuentren adscritos; la transformación de las relaciones interpersonales no es asunto que sencillo, pero, si es una herramienta que ayuda a generar una percepción distinta del conflicto y la disminución de los comportamientos violentos, creemos que es válido acudir a su uso.

Para la implementación de la justicia restaurativa en el Estado de Nuevo León es necesario tomar de base las experiencias que otros países han tenido en el tema de acuerdo al Informe de la Reunión del Grupo de Expertos sobre Justicia Restaurativa del Comisión de Prevención del Delito y Justicia Penal del Consejo Económico y Social de Naciones Unidas de fecha 7 de enero de 2002.

Es menester utilizar la definición de justicia restaurativa contenida en la Fracción XV del Artículo $2^{\mathbf{o}}$ de la Ley de Mecanismos Alternativos para la Solución de Controversias para el Estado de Nuevo León publicada el 13 de enero de 2017, referida como un mecanismo mediante el cual las partes de una controversia se involucran para identificar y atender colectivamente las consecuencias del hecho o conducta que se reclama y las necesidades y obligaciones de cada uno de los interesados a fin de resolver el conflicto, esto con el propósito de lograr la reintegración en la comunidad, la recomposición social, así como la reparación del daño o perjuicio causado, o ambos, en su caso.

Ahora bien, se requiere de un cambio de paradigma para que la justicia restaurativa sea utilizada en campos distintos al ámbito penal, sería necesario ampliar el enfoque a ámbitos como el comunitario y familiar, sin limitar su aplicación, lo que traería como consecuencia la necesidad de capacitación especializada en dichos campos para analizar, de acuerdo al conflicto, el tipo de práctica restaurativa que conviene utilizar.

Como referencia conviene citar el último párrafo del artículo 24 de la Ley de Mecanismos Alternativos para la Solución de Controversias para el Estado de Nuevo León, el cual establece que la justicia restaurativa se podrá aplicar para la reparación del daño o perjuicio derivados de cualquier controversia, independientemente de su origen o materia, sin embargo, la justicia restaurativa, para los términos de esta ley, únicamente se podrá aplicar para solucionar controversias que se susciten en materia familiar, civil, escolar y comunitaria.

\subsection{Objetivos de la justicia restaurativa.}

En relación a lo anterior, entendemos que los objetivos de la justicia restaurativa son:

a) Cada individuo debe asumir la responsabilidad de los hechos que dieron origen al conflicto, particularmente el ofensor, así como participar en su solución y en el compromiso de no repetición de la conducta ofensiva.

b) Reparar el daño a la víctima, a fin de restaurar lo afectado por el ofensor, en su caso, por ambos.

c) Reintegrar al infractor con la sociedad a la cual pertenece, fortaleciendo la dinámica funcional de sus integrantes, a fin de alcanzar la recomposición del tejido social. 
SAUCEDA, Brenda; GORGÓN, Gabriel. “Justicia restaurativa, una herramienta de paz en la resolución de conflictos comunitarios. Caso Nuevo León”.

\subsection{Justicia restaurativa y mediación comunitaria.}

Desde nuestro punto de vista, la justicia restaurativa y la mediación son distintas. El artículo 24 de la Ley de Mecanismos Alternativos para la Solución de Controversias para el Estado de Nuevo León señala que la justicia restaurativa se podrá obtener a través de cualquier metodología a elección de las partes, incluidos los mecanismos alternativos contemplados por la misma Ley, únicamente debiendo de observar los siguientes principios:

“a) Encuentro entre los intervinientes;

b) Enmiendas acordadas por las partes como compensación o restauración del daño y/o perjuicio sufrido por la parte ofendida, sea de naturaleza moral o patrimonial;

c) Reintegración dentro de la comunidad para la parte ofensora; y

d) Inclusión de todas las partes dentro del proceso de justicia restaurativa."

La justicia restaurativa puede ser utilizada como un procedimiento independiente de cualquier mecanismo alternativo de solución de conflictos, ya que la justicia restaurativa cuenta con estrategias que consideramos conveniente denominar prácticas restaurativas, me permitiré citar únicamente aquellas que están relacionadas con el ámbito comunitario:

a) Junta restaurativa (Reuniones de víctima-infractor-comunidad). El Artículo 27 de la Ley Nacional de Mecanismos Alternativos de Solución de Controversias en Materia Penal publicada en el Diario Oficial de la Federación en fecha 29 de diciembre de 2014 conceptualiza a la junta restaurativa como "aquel mecanismo mediante el cual la víctima u ofendido, el imputado y, en su caso, la comunidad afectada, en libre ejercicio de su autonomía, buscan, construyen y proponen opciones de solución a la controversia, con el objeto de lograr un Acuerdo que atienda las necesidades y responsabilidades individuales y colectivas, así como la reintegración de la víctima u ofendido y del imputado a la comunidad y la recomposición del tejido social."

b) Círculo restaurativo (círculo de paz o círculo de ayuda). "Los círculos son una práctica restaurativa en la cual suelen participar todas aquellas personas que forman parte de un conflicto y quienes colaboran en su solución; se colocan en un círculo, o en varios, y tienen la oportunidad de narrar su vivencia, expresar sus sentimientos, debatir y llegar a acuerdos, a fin de buscar respuestas y conocer necesidades; para que la participación sea equitativa se utiliza un objeto, como símbolo que propicie la reflexión o la identidad de los participantes"27.

c) Conferencia restaurativa. "Las conferencias son dinámicas que sirven para desarrollar un diálogo reparador, sin olvidar el vínculo comunitario, que puede materializarse, en su caso, con el desarrollo de trabajos y prestaciones al servicio de la comunidad." 28 "Los participantes en las conferencias, generalmente son, además de la víctima y el victimario, las personas más cercanas a ellos, familiares y amigos, y en algunas ocasiones también personas de la comunidad; sin embargo, hay ocasiones en que la participación de la víctima y su entorno no se exige o no es posible, por ésta razón el International Institute for Restorative Practices

${ }^{27}$ CHOYA FORÉS, Nastia. "Prácticas Restaurativas: Círculos y Conferencias". País Vasco: Justicia restaurativa: nuevas perspectivas en mediación, 2014-2015, pp. 1-50, p. $14 \quad \mathrm{y} 24$, en: http://www.sociedadvascavictimologia.org/images/documentos/Materiales\%20postgrado/9\%20JUSTICIA\%20REST AURATIVA/PRACTICAS\%20RESTAURATIVAS.pdf.

${ }^{28}$ IGARTUA, I.; OLALDE, A.; y VARONA, G., en CHOYA FORÉS, Nastia. "Prácticas Restaurativas”, cit. nota núm. 2, 2014-2015, p. 9. 
Polít. crim. Vol. 13, No 25 (Julio 2018) Art. 14, pp. 548 -

[http://www.politicacriminal.cl/Vol_13/n_25/Vol13N25A14.pdf]

(IIRP) no considera las conferencias, en las que no participa la víctima, como parte de la justicia restaurativa y prefieren denominarlas justicia comunitaria"29.

d) Prácticas indígenas o de costumbres. "Están siendo adaptadas para el uso en el sistema de justicia penal. Colombia es uno de estos casos, pues la Constitución de 1991 creo la Jurisdicción Indígena en la que se permite a las comunidades nativas aplicar sus formas tradicionales de justicia, algunas de ellas con sentido restaurativo" 30 .

e) Mesas comunitarias de reparación. "Esta es una versión nueva de los conocidos Paneles Juveniles, Junta de Vecinos y Grupos de Comunidad. Este tipo de reuniones se realizan en Estados Unidos desde los años 20 del siglo pasado, la nueva versión data de los años 90. Fueron usadas para tratar casos de delitos de adultos que no implicaban violencia o en delitos menores, actualmente se usan en delincuencia juvenil. Las Mesas Comunitarias son integradas por pequeños grupos de ciudadanos/as previamente entrenados para lograr encuentros cara a cara víctima-ofensor/a, cuando la corte ha exigido este procedimiento. Estas Mesas desarrollan acuerdos con los ofensores, hacen seguimiento a su cumplimiento y reportan a la corte." 31

f) Conferencias de grupos de familias. "Son espacios de encuentro y conciliación entre las familias en conflicto." 32

g) Procesos restauradores. "Están siendo utilizados para mostrar y tomar en cuenta los conflictos entre ciudadanos y el gobierno." 33

Por otra parte, la mediación es un mecanismo alternativo de solución de conflictos llevado a cabo a través de un facilitador que guía a las partes a llegar a un acuerdo de forma voluntaria, en el ámbito comunitario; no obstante, la mediación comunitaria puede basarse en una filosofía con enfoque restaurativo, es decir, con los objetivos de la justicia restaurativa mencionadas anteriormente, y con un objetivo dirigido hacia la satisfacción de las necesidades de las personas, la reparación del daño, la transformación de las relaciones interpersonales.

En el contexto social urbano del Estado de Nuevo León en México la mediación comunitaria es un método alterno de solución de conflictos, derivada de las generalidades propias de toda mediación, en la que participan como intervinientes los vecinos de una determinada comunidad, y uno o más facilitadores del ámbito público o privado, capacitados y debidamente certificados por el Instituto de Mecanismos Alternativos para la Solución de Controversias del Consejo de la Judicatura del Poder Judicial del Estado de Nuevo León, quienes intervienen como guías para lograr acuerdos, fomentando la participación, relaciones sanas entre los vecinos, el sentido de pertenencia, a fin de alcanzar el bien común y la recomposición del tejido social.

Cabe hacer la aclaración que la justicia restaurativa y la mediación comunitaria pudiera parecer lo mismo, pero consideramos que la mediación comunitaria sigue un procedimiento genérico de mediación con el uso de técnicas comunicativas a fin de llegar a un acuerdo; mientras que la justicia

${ }^{29}$ CHOYA, "Prácticas Restaurativas", cit. nota núm. 3, 2014-2015, p. 9.

30 BRITTO RUIZ, Diana. Justicia restaurativa: Reflexiones sobre la experiencia de Colombia, Ecuador: Editorial Universidad Técnica Particular de Loja, 2010, pp. 1-142, p. 35.

${ }^{31}$ BRITTO, Justicia restaurativa, cit., nota núm.2, 2010, p. 42.

${ }^{32}$ BRITTO, Justicia restaurativa, cit., nota núm.3, 2010, p. 87.

${ }^{33}$ BRITTO, Justicia restaurativa, cit., nota núm. 4, 2010, p. 36. 
SAUCEDA, Brenda; GORGÓN, Gabriel. "Justicia restaurativa, una herramienta de paz en la resolución de conflictos comunitarios. Caso Nuevo León”.

restaurativa, además de utilizar técnicas comunicativas, permite el uso de estrategias sanadoras, para alcanzar el perdón y la reconciliación; sin embargo, admitimos que la mediación comunitaria, además de las etapas de la mediación, puede utilizar estrategias sanadoras, para lo cual se requiere de mayor creatividad y sensibilización por parte del facilitador.

Tanto la justicia restaurativa como la mediación comunitaria con enfoque restaurativo, deben ser aplicadas acorde a los intereses y necesidades de las personas, como el elemento imprescindible en ambas es la voluntariedad, de este modo debemos advertir que no todos los contextos permiten su aplicación; al respecto es conveniente citar el Artículo 18, párrafo sexto de la Constitución Política de los Estados Unidos Mexicanos que a la letra dice:

“... Las formas alternativas de justicia deberán observarse en la aplicación de este sistema, siempre que resulte procedente..."

El estudio de la justicia restaurativa en materia penal ha considerado como partes interesadas primarias a las víctimas y los delincuentes que son quienes resultan más afectadas, pero también las comunidades de apoyo, es decir, quienes tienen una conexión afectiva importante con ellos, como los padres, cónyuges, hermanos, amigos, que también se ven afectados directamente ${ }^{34}$.

Las partes interesadas secundarias sufren daños indirectos e impersonales, sus necesidades son colectivas e inespecíficas, y su respuesta restaurativa está en apoyar los procedimientos restaurativos en general; son personas que viven cerca, como los vecinos, o aquellas que pertenecen a organizaciones educativas, religiosas, sociales o comerciales. Igualmente se incluye a toda la sociedad, representada por funcionarios del gobierno ${ }^{35}$.

En lo que corresponde a la atención de los conflictos comunitarios, la mayoría de los Municipios del Área Metropolitana de Monterrey, Nuevo León han creado Centros de Mediación Municipales y/o han implementado un programa de policía de proximidad; sin embargo, los esfuerzos no son suficientes, la tarea no es sólo del Estado, la tarea principal de éste debe ser preservar el orden, y por su parte los miembros de la comunidad tienen el deber de participar en el desarrollo de los métodos alternos de solución de conflictos y en la promoción de la cultura de paz que el propio Estado implemente, por lo que hace falta direccionar dichos esfuerzos en ese sentido.

La justicia restaurativa es una filosofía que puede tornarse como directriz rectora de la mediación comunitaria garantizando el respeto por los derechos humanos, el diálogo y la cultura de paz, siendo necesario para su implementación el apoyo del Estado o Municipio, organizaciones de la sociedad civil, actores sociales y miembros de la comunidad para capacitarlos e implementar de manera eficaz la paz social.

En suma, la justicia restaurativa en el campo comunitario es una salida alterna, pero también puede considerarse a la mediación comunitaria como método alterno de solución de conflictos con enfoque restaurativo en su aplicación a los conflictos comunitarios. En este sentido puede

\footnotetext{
${ }^{34}$ SAMPEDRO ARRUBLA, Julio Andrés, “¿Qué es y para qué sirve la Justicia Restaurativa?”, Revista Derecho Penal, núm. 12 (2005), pp. http://legal.legis.com.co/document?obra=rpenal\&document=rpenal_7680752a8057404ce0430a010151404c

${ }^{35}$ SAMPEDRO, “¿Qué es y para qué sirve la Justicia Restaurativa?”, cit. nota núm. 2.
} 
Polít. crim. Vol. 13, No 25 (Julio 2018) Art. 14, pp. 548 -

[http://www.politicacriminal.cl/Vol_13/n_25/Vol13N25A14.pdf]

considerarse el contenido de los Artículos 7 y 8 de la Ley Nacional de Mecanismos Alternativos de Solución de Controversias en Materia Penal, referente a los derechos y obligaciones de los intervinientes en los procedimientos alternativos.

Consideramos que tanto en la mediación comunitaria como en la justicia restaurativa pudiera parecer poco indispensable firmar un acuerdo reparatorio o de mediación para resolver un conflicto, es probable que aun así sean alcanzados los objetivos mencionados con antelación: la satisfacción de las necesidades de las personas, la reparación del daño, la transformación de las relaciones interpersonales y alcanzar el perdón y la reconciliación.

Ahora bien, cabe la posibilidad de que un procedimiento que inicie como mediación conforme al Artículo 22 de la Ley Nacional de Mecanismos Alternativos de Solución de Controversias en Materia Penal, cambien las condiciones para propiciar el procedimiento que señala el Artículo 28 referente a la junta restaurativa, siempre y cuando se cuente con la voluntad de las partes y no se encuentra fuera del orden jurídico. Al respecto, encontramos el fundamento de la sustitución del mecanismo alternativo en el Artículo 30 de la mencionada ley, en referencia al supuesto de que los intervinientes hubieren participado en alguno de los mecanismos alternativos y no se hubiese logrado por este mecanismo la solución de la controversia, el facilitador podrá sugerirles que recurran a uno diverso.

\subsection{La reparación del daño con efectos restaurativos.}

De acuerdo al proyecto de la Ley Nacional de Mecanismos Alternativos de Solución de Controversias en Materia Penal, uno de los objetivos de las reformas es privilegiar la reparación del daño, así como la restauración del tejido social. El acuerdo reparatorio es una forma de solución alterna del procedimiento y es aquél celebrado entre la víctima u ofendido y el imputado que, una vez aprobado por el Ministerio Público o el Juez de Control y cumplido en sus términos, tienen como efecto la extinción de la acción penal ${ }^{36}$.

La Ley General de Víctimas ${ }^{37}$ señala que "las compensaciones a las víctimas se otorgará por todos los perjuicios, sufrimientos y pérdidas económicamente evaluables que sean consecuencia de la comisión de los delitos a los que se refiere el artículo 68 o de la violación de derechos humanos", dicho precepto responsabiliza a la Comisión Ejecutiva para cubrir la compensación de forma subsidiaria para asegurar su cumplimiento, con cargo al Fondo, cuando la Comisión de víctimas de la entidad federativa lo solicite por escrito en términos de lo previsto en la fracción XVII del artículo 81 de la Ley. Además de la compensación, dicha ley señala como medidas para efectuar la reparación integral la restitución, rehabilitación, satisfacción y garantías de no repetición.

Ahora bien, en el análisis de la reparación del daño de los delitos penales de menor cuantía o de menor grado de peligrosidad, notamos que no dista de la reparación pretendida en los conflictos comunitarios, por ello continúo con el argumento que realiza la autora Virginia Domingo respecto a la reparación del daño en el ámbito jurídico penal al considerar el restablecimiento del orden

\footnotetext{
${ }^{36}$ Artículos 184 y 186 del Código Nacional de Procedimientos Penales.

${ }^{37}$ Artículo 64 de dicha ley.
} 
SAUCEDA, Brenda; GORGÓN, Gabriel. “Justicia restaurativa, una herramienta de paz en la resolución de conflictos comunitarios. Caso Nuevo León”.

jurídico perturbado por la comisión del hecho delictivo, en este sentido cita varias clases de reparación, que se podrán aplicar a los procesos restaurativos, con ciertos matices ${ }^{38}$ :

"Reparación económica: En un proceso restaurativo la concreción de cantidades sólo responde a los criterios de las partes, entonces la reparación económica se subjetiviza, alejándose de la responsabilidad ex delicto que objetivamente se hubiese impuesto en el procedimiento judicial, pudiendo ser inferior a la responsabilidad civil peritada. A veces se repara en exceso, aceptado por el infractor, o a veces existe defecto de reparación o renuncia de la víctima a la misma, por satisfacción o por otras formas de reparación que pudiera haber.

Reparación de los perjuicios personales y morales: Esta forma de reparación es la que más directamente busca solucionar el conflicto entre las partes. Aquí se puede destacar, la petición de perdón por el infractor y su consiguiente aceptación por la víctima.

Reparación de actividad: Existen tres requisitos que deben definir la reparación como actividad: Carácter público, búsqueda directa de resocialización del infractor y concreción en espacio y tiempo de la medida. Estas actividades le reportan a la víctima una reparación moral al saber que el autor del delito realizará esfuerzos que expresaran su arrepentimiento y su voluntad de no reincidir. Además, contienen una idea amplia de reparación abarcando también a la comunidad en general, contribuyendo a atender las necesidades de las víctimas."

El artículo 29 de la Ley Nacional de Métodos Alternos de Solución de Conflictos en materia penal señala que la reparación del daño derivada del procedimiento restaurativo podrá comprender lo siguiente:

"I. El reconocimiento de responsabilidad y la formulación de una disculpa a la víctima u ofendido en un acto público o privado, de conformidad con el Acuerdo alcanzado por los intervinientes, por virtud del cual el imputado acepta que su conducta causó un daño;

II. El compromiso de no repetición de la conducta originadora de la controversia y el establecimiento de condiciones para darle efectividad, tales como inscribirse y concluir programas o actividades de cualquier naturaleza que contribuyan a la no repetición de la conducta o aquellos programas específicos para el tratamiento de adicciones;

III. Un plan de restitución que pueda ser económico o en especie, reparando o reemplazando algún bien, la realización u omisión de una determinada conducta, la prestación de servicios a la comunidad o de cualquier otra forma lícita solicitada por la víctima u ofendido y acordadas entre los intervinientes en el curso de la sesión."

Ron Claassen, quien ha trabajado en el campo de la justicia restaurativa durante muchos años, dice que, para resolver cualquier tipo de injusticia, hay que lograr tres cosas: "1. Que se reconozca el daño o la injusticia; 2. Que se restaure la equidad; y 3. Que se discutan los planes y expectativas para el futuro" 39 .

\footnotetext{
${ }^{38}$ DOMINGO, Virginia. Contexto teórico-práctico de la justicia restaurativa en Europa con especial a España, Guayaquil, Ecuador: Ponencia impartida en el Congreso Internacional Ciencia Penal y Justicia Penal Restaurativa, Una mirada hacia la Justicia Restaurativa: Recuperando el derecho perdido, Criminología y justicia, (2011), pp. 7083, p. 74 y 75.

${ }^{39}$ CLAASSEN, Ron en ZEHR, El pequeño libro, cit. nota núm. 3, p. 55.
} 
Polít. crim. Vol. 13, No 25 (Julio 2018) Art. 14, pp. 548 -

[http://www.politicacriminal.cl/Vol_13/n_25/Vol13N25A14.pdf]

De lo anterior, podemos advertir que la reparación del daño que resulte del acuerdo reparatorio puede ser de índole económica relativa a los perjuicios personales y morales y de actividad, con lo cual tenemos la posibilidad de que la reparación se brinde a través de otros medios distintos a los económicos, lo que ofrece a las víctimas y ofensores un panorama amplio de posibilidades para dar cumplimiento a dicha reparación ${ }^{40}$.

Los jueces de primera instancia tienen la obligación de promover la justicia alternativa posibilitando la producción del acuerdo reparatorio que extinga la acción penal, con dicho acuerdo se evita no sólo la imposición de penas, sino la instrumentación del proceso penal; por ello es importante la intervención obligatoria del Ministerio Público, desde su primera intervención y hasta antes del dictado de la sentencia, y del Juez, a fin de invitar a las partes a participar en el proceso restaurativo y acceder a los métodos alternos, conforme a la siguiente tesis aislada emitida por el Segundo Tribunal Colegiado en Materia Penal del Tercer Circuito:

JUSTICIA ALTERNATIVA EN EL ESTADO DE JALISCO. SI EN EL AMPARO DIRECTO EL TRIBUNAL COLEGIADO DE CIRCUITO ADVIERTE QUE EN EL PROCESO RESPECTIVO NO SE CONVOCÓ A LAS PARTES PARA EL DESAHOGO DE LA AUDIENCIA A QUE SE REFIERE EL ARTÍCULO 56-BIS DE LA LEY RELATIVA, ELLO ACTUALIZA UNA VIOLACIÓN A LAS LEYES DEL PROCEDIMIENTO EN TÉRMINOS DEL ARTÍCULO 160, FRACCIÓN V, DE LA LEY DE AMPARO, VIGENTE HASTA EL 2 DE ABRIL DE 2013, QUE ORIGINA SU REPOSICIÓN Y QUE SE ORDENE SU CELEBRACIÓN. Conforme al artículo 110 de la Ley Orgánica del Poder Judicial del Estado de Jalisco, los Jueces de primera instancia tienen la obligación de promover los medios alternativos de solución de conflictos a las partes, otorgando la posibilidad de producir un eventual acuerdo reparatorio cuyo cumplimiento pudiera generar la extinción de la acción penal, en términos de los artículos 72 de la Ley de Justicia Alternativa y 308, fracción IX, del Código de Procedimientos Penales, ambos para esa entidad. Ahora bien, si en el amparo directo el Tribunal Colegiado de Circuito advierte que en el proceso respectivo no se les convocó para el desahogo de la audiencia a que se refiere el artículo 56-Bis de la citada Ley de Justicia Alternativa, ello origina una violación a las normas rectoras del procedimiento de origen y a su vez a los derechos fundamentales del sentenciado quejoso que trasciende al resultado del fallo, en términos del artículo 160, fracción V, de la Ley de Amparo, vigente hasta el 2 de abril de 2013. Ello es así, si se tiene presente que con tales medios de solución se evita no sólo la imposición de penas, sino la instrumentación del proceso; de ahí que sea obligación del Ministerio Público, desde su primera intervención y hasta antes del dictado de la sentencia, y del Juez, invitar a las partes a participar en el proceso restaurativo y acceder a los métodos alternos a través de la mencionada audiencia. Luego, la falta de su celebración impide a las partes utilizar los beneficios que la legislación procesal establece para solucionar el litigio e impide al probable responsable del delito ejercer su derecho para no ser sometido a un proceso penal. Por tanto, procede conceder el amparo para que la responsable ordene reponer el procedimiento de primera instancia a efecto de que el Juez invite a las partes a la celebración de la citada diligencia. Amparo directo 413/2012. 6 de junio de 2013. Unanimidad de votos. Ponente: Hugo Ricardo Ramos Carreón. Secretaria: María del Carmen Cabral Ibarra.

Es importante apuntar que, además de las normas y la tesis mencionada, la justicia restaurativa debe ser aplicada conforme a la nueva Ley Nacional del Sistema Integral de Justicia Penal para Adolescentes publicada en el Diario Oficial de la Federación el 16 de junio de 2016, la cual

${ }^{40}$ Como lo establecimos líneas atrás: $\mathrm{A}+\mathrm{B}=$ Puede ser D, E o F. 
SAUCEDA, Brenda; GORGÓN, Gabriel. "Justicia restaurativa, una herramienta de paz en la resolución de conflictos comunitarios. Caso Nuevo León”.

contempla el término de 3 años para incorporar los requerimientos necesarios para la plena operación de dicho Sistema.

Otra norma recientemente aprobada a considerar en este tema es la Ley Nacional de Ejecución Penal publicada el 16 de junio de 2016, misma que entrará en vigor el 30 de noviembre del 2018, la cual tiene relevancia para una adecuada implementación de la justicia restaurativa, en base a principios de carácter socioeducativo, proporcionalidad, mínima intervención y autonomía progresiva.

\section{La necesidad de implementación de las prácticas restaurativas en la comunidad.}

Jorge Carpizo destaca que la tendencia moderna es establecer diversos mecanismos jurídicos para que los derechos de la justicia social sean exigibles, aunque no todos revistan carácter jurisdiccional. Luigi Ferrajoli, sostiene que el paradigma garantista de la democracia constitucional actualmente es embrionario, debe y puede extenderse en una dirección triple: a) para garantizar tanto los derechos de libertad como los sociales; b) frente a todos los poderes, tanto los públicos como los privados, y c) tanto en el nivel de derecho interno como en el internacional ${ }^{41}$.

Según Howard Zehr, lo que las comunidades necesitan de la justicia es:

"1. Atención a sus necesidades como víctimas.

2. Oportunidades para desarrollar un sentido de comunidad y responsabilidad de los unos por los otros.

3. Motivación para asumir sus responsabilidades en pro del bienestar de todos sus miembros, incluidas las víctimas y los ofensores y fomentar las condiciones para crear y sostener comunidades sanas." 42

La exigibilidad procesal de los derechos sociales y civiles es uno de los problemas que enfrenta la ciudadanía, y se presenta debido a la falta de capacidad de los tribunales para dar respuesta a las demandas que aquejan a la sociedad; además de la incapacidad económica del Estado para la creación de nueva infraestructura judicial para enfrentar los retos actuales. En base a dicha necesidad, los procesos judiciales tienden a resolverse después de un tiempo prolongado y conlleva un extenuante desgaste económico y emocional para las partes en litigio, por lo que, en los conflictos de menor cuantía, muchas veces las partes prefieren no acudir a los tribunales o simplemente sobrellevan los conflictos porque piensan que perderán su tiempo y dinero, desconfiando en la impartición de justicia pronta y expedita.

En el Capítulo IV del Título Segundo de la Ley Nacional de Mecanismos Alternativos de Solución de Controversias en Materia Penal, se regula el procedimiento restaurativo, y en la iniciativa de decreto del 4 de Marzo de 2014 se destaca que la característica principal de dicho procedimiento es la posibilidad de que además de las personas directamente involucradas en el hecho presuntamente delictivo, participe la comunidad en la que los intervinientes directos están

\footnotetext{
${ }^{41}$ CARPIZO, Jorge. "Los derechos de la justicia social: Su protección procesal en México". Boletín Mexicano de Derecho Comparado, Volumen XLV, No. 135, (2012), pp. 1079-1110, p. 1080, en: http://www.scielo.org.mx/pdf/bmdc/v45n135/v45n135a6.pdf

42 ZEHR, El pequeño libro, cit. nota núm. 4, p. 24.
} 
Polít. crim. Vol. 13, No 25 (Julio 2018) Art. 14, pp. 548 -

[http://www.politicacriminal.cl/Vol_13/n_25/Vol13N25A14.pdf]

inmersos, con el fin de lograr el reconocimiento de las responsabilidades individuales y colectivas e incentivar la recomposición del tejido social.

Si bien es cierto que los distintos ámbitos de gobierno del Estado de Nuevo León han tenido avances significativos en la adaptación de nuevos modelos y procedimientos que respondan a las demandas actuales, en el tema que nos ocupa, tenemos que en materia penal se han iniciado programas de justicia restaurativa y recientemente también en materia familiar, con un Tribunal de Justicia Familiar Restaurativa, mismo que fue anunciado a mediados del año 2015 ${ }^{43}$; sin embargo, no debemos pasar por alto la viabilidad de la implementación de proyectos piloto de justicia restaurativa en el contexto comunitario, ya que depende del conocimiento que tengan las autoridades y los actores sociales sobre este tema para que puedan ser implementadas con la finalidad de disminuir la violencia en la sociedad.

El enfoque de la justicia restaurativa en el ámbito comunitario, ya sea desde la perspectiva de que la comunidad sea parte afectada en el proceso restaurativo, o como coadyuvante en la solución de determinada controversia, participando en la reintegración de la víctima u ofendido y reinserción social del imputado a la misma comunidad, atendiendo las necesidades y responsabilidades individuales y colectivas de acuerdo al Artículo 27 de la Ley Nacional de Mecanismos Alternativos de Solución de Controversias en Materia Penal.

Asimismo, el Artículo 32 de la Convención Americana de Derechos Humanos, establece que toda persona tiene deberes para con la comunidad, ya que como dice el Artículo 29 de la Declaración Universal de los Derechos Humanos, sólo en ella puede desarrollar libre y plenamente su personalidad; además que los derechos de cada persona están limitados por los derechos de los demás, por la seguridad de todos y por las justas exigencias del bien común, en una sociedad democrática.

Por ello, es importante considerar la justicia restaurativa en la comunidad como prácticas de inclusión en el que los ciudadanos que forman parte de la comunidad son partícipes, con la finalidad no sólo de reparar el daño material ocasionado, sino atendiendo la raíz del conflicto, con la visión integral de lograr el perdón y la reconciliación, lo que por consecuencia crea vínculos individuales y colectivos con el paradigma de la cultura de paz, mejorando la calidad de vida de la ciudadanía y colaborando en la construcción de la justicia social.

No obstante, debemos considerar que, en ocasiones, las condiciones del contexto comunitario pueden perjudicar en el desarrollo y ejecución de programas de justicia restaurativa o prácticas restaurativas, por lo que es importante el diseño, planeación y educación sobre dichas prácticas, para evitar en la medida de lo posible resultados poco favorables.

Alberto Binder señala que el conflicto es propio de la naturaleza humana y tenemos que saber convivir con él, es impensable una sociedad sin conflictos, ya que este representa los intereses, el cambio y la evolución necesarios para la especie humana. Las fuentes de conflictos no se convierten automáticamente en causas de él, se requieren condiciones de contexto para que esto ocurra ${ }^{44}$.

\footnotetext{
${ }^{43}$ VALDEZ, C., “Análisis jurídico y político”, Revista Equidad, (2014), en: http://revista-equidad.com/?p=21291
}

${ }^{44}$ BINDER, Alberto, Análisis Político Criminal, Buenos Aires: Editorial Astrea, 2011, p. 151. 
SAUCEDA, Brenda; GORGÓN, Gabriel. "Justicia restaurativa, una herramienta de paz en la resolución de conflictos comunitarios. Caso Nuevo León”.

Las prácticas restaurativas brindan espacios para facilitar encuentros, las características de los intervinientes y cómo se desarrolla cada una son factores que las distingue, sin embargo, no existe limitante alguna para adoptar una combinación de distintas prácticas de tipo restaurativo.

El Manual sobre Programas de Justicia Restaurativa de la Organización de Naciones Unidas ${ }^{45}$, señala que hay cierto número de problemas a considerar para involucrar totalmente a la comunidad en prácticas de justicia restaurativa. Estos incluyen:

a) ¿Cuáles son las jerarquías y dinámicas de poder en la comunidad que pueden afectar qué miembros de la comunidad se involucran y qué impacto tienen en el proceso restaurativo?

b) ¿Qué lineamientos definirán quién debe ser incluido en el proceso restaurativo?

c) ¿Qué estrategias pueden utilizarse para movilizar soporte comunitario y mantener el Participación de residentes en programas de justicia restaurativa como mediadores, facilitadores y mentores?

d) ¿Qué estrategias pueden desarrollarse para minimizar cualquier impacto negativo potencial de las iniciativas de justicia restaurativa sobre la comunidad involucrada en ellas?

e) ¿Qué entrenamiento y habilidades se requieren para que los residentes de la comunidad puedan participar en programas de justicia restaurativa?

f) ¿Hasta qué grado los residentes de la comunidad sin capacitación especializada pueden participar en procesos de justicia restaurativa?

g) ¿Qué estructuras y procesos existentes pueden proporcionar una base para programas de justicia restaurativa?

Es imprescindible realizar un diagnóstico de la comunidad y los conflictos que les aquejan para determinar las estrategias a tomar y para la elaboración de un plan de trabajo, y en su momento para la realización de un seguimiento posterior a la finalización del programa.

\section{Conclusiones}

La justicia restaurativa aplicada en el contexto comunitario fortalece los vínculos colectivos e individuales entre los ciudadanos; debe ser considerada como un proceso alternativo de solución de controversias que garantiza los derechos humanos preservando el principio pro homine que implica que la interpretación jurídica siempre debe buscar el mayor beneficio para el hombre ${ }^{46}$, debe preverse el efecto útil de los tratados internacionales de acuerdo al contexto de aplicación de éstos y teniendo en cuenta su objeto y fin conforme al Artículo 31.1 de la Convención de Viena; y por último, debe tomarse en cuenta que dicho proceso propicia el diálogo y genera la cultura de paz entre los habitantes de las comunidades.

Es importante identificar la cultura de organización, participación y sentido de pertenencia de cada comunidad para tomar decisiones en el emprendimiento de las prácticas restaurativas como herramientas que fomenten la cultura de paz, por ello nos permitimos considerar que la paz social y la seguridad pública pueden ser el motor que incentive a los ciudadanos a participar en la solución de conflictos comunitarios que puedan ser tipificados por la ley como delitos o faltas civiles o administrativas, de acuerdo a las leyes vigentes en el Estado.

\footnotetext{
${ }^{45}$ ONU, "Manual de programas de justicia restaurativa", cit. nota número 2, p. 57.

${ }^{46}$ PRINCIPIO PRO HOMINE. Su aplicación es obligatoria, Amparo directo 202/2004, Cuarto Tribunal Colegiado en Materia Administrativa del Primer Circuito, 20 de octubre de 2004.
} 
Polít. crim. Vol. 13, No 25 (Julio 2018) Art. 14, pp. 548 -

[http://www.politicacriminal.cl/Vol_13/n_25/Vol13N25A14.pdf]

Las personas directamente involucradas en las prácticas restaurativas son el ofensor y el agraviado; los participantes indirectos son el Estado y la comunidad, tomando en cuenta en ella a las personas físicas y a instituciones como la iglesia, la escuela y las organizaciones no gubernamentales de la sociedad civil, quienes trabajarán en forma planificada por la reinserción y/o reintegración social de los vecinos que hayan sido o no privados de la libertad, con el objetivo de reparar el daño, llegar a la recomposición del tejido social.

En cuanto a las figuras que además podrían participar en los procedimientos restaurativos en el campo comunitario urbano en el Estado de Nuevo León encontramos a los llamados jueces auxiliares o de barrio y/o delegados municipales o los jueces de paz, por lo que de acuerdo a la concepción que se tenga de cada uno de ellos, el órgano competente puede ser municipal o estatal, con dependencia del Ayuntamiento Municipal o del Poder Judicial Estatal, quienes una vez capacitados, podrían colaborar con las áreas mencionadas líneas atrás.

La organización de la comunidad puede propiciar el estudio de otra figura conocida como justicia comunitaria, la cual es una institución de derecho consuetudinario que permite sancionar las conductas reprobadas de los individuos pero sin la intervención del Estado, sus jueces y su burocracia, sino directamente dentro de la comunidad de individuos en la que las autoridades naturales de la comunidad hacen de equilibrantes entre las dos partes enfrentadas ${ }^{47}$; no descartamos que ésta figura como tal o la justicia restaurativa sin la intervención estatal, pueda desarrollarse con fines restaurativos, ya que existen comunidades que han establecido sus redes sociales o de apoyo y normas internas que ayudan a sus miembros a actuar de manera efectiva y a perseguir objetivos en conjunto.

Respecto al ámbito de competencia, el Artículo 40 de la Constitución Política de los Estados Unidos Mexicanos, señala que cada Entidad Federativa tiene facultades para regular su régimen interior, por lo que corresponde a cada Estado realizar los ajustes legales que determinen el nombramiento de los funcionarios que atenderían los conflictos comunitarios, en su caso de materias civil, familiar o penales mediante procedimientos de justicia restaurativa.

Resulta factible y viable la implementación de programas de justicia restaurativa por parte del Estado de Nuevo León en el campo comunitario, para lo cual se requiere comenzar con un proyecto piloto, lo cual de acuerdo a lo señalado ante la Organización de Naciones Unidas en el Informe de la reunión del Grupo de Expertos sobre Justicia Restaurativa y conforme al Manual sobre Programas de Justicia Restaurativa, en donde se afirma que son mayores las ventajas que las desventajas en su uso.

Cada proyecto debe ser estudiado para definir una intervención específica para cada caso; también es importante apuntar que se requiere de un equipo interdisciplinario de especialistas en las ciencias sociales como las áreas legal, psicología, trabajo social, sociología, antropología y criminología, por lo cual genera la necesidad de un presupuesto suficiente para el gasto por concepto de nómina y otras necesidades de recursos materiales necesarios.

47 MACHICADO, J., “Apuntes jurídicos”. (2015), en: http://jorgemachicado.blogspot.mx/2009/01/justiciacomunitaria.html 
SAUCEDA, Brenda; GORGÓN, Gabriel. "Justicia restaurativa, una herramienta de paz en la resolución de conflictos comunitarios. Caso Nuevo León”.

Como vimos, en materia penal, la Ley General de Víctimas señala un fondo con recurso económico con el que cuenta la Comisión Ejecutiva de Atención a Víctimas Estatal o Federal, dependiendo si el delito cometido corresponde al ámbito local o federal, la cuestión es que ese recurso puede emplearse para la implementación de programas de justicia restaurativa, o podría crearse una Unidad Especializada de Justicia Restaurativa en el Estado.

La reparación del daño debe ser integral, oportuna, plena, diferencial, transformadora y efectiva, y debe realizarse mediante un plan de reparación que incluya las medidas, plazos y modalidades de cumplimiento, respetando los principios de proporcionalidad, causalidad, complementariedad, especialidad, jerarquía y progresividad, conforme a la Ley General de Víctimas.

Para lograr mayores resultados en la implementación de la Ley Nacional del Sistema Integral de Justicia Penal para Adolescentes, se requieren acciones tendientes a evaluar las comunidades de donde provienen los adolescentes en conflicto con la ley a fin de trabajar con los miembros del contexto social donde se desarrollarán para lograr su reinserción social, además de brindarles atención y seguimiento en sus necesidades a través de las redes interinstitucionales y comunitarias de apoyo.

Por último, respecto a la Ley Nacional de Ejecución Penal se requiere respetar los principios contenidos en la misma y que las autoridades corresponsables trabajen en coordinación con la unidad encargada de los servicios post-penales dentro de la autoridad penitenciaria, que establezcan centros de atención y formar redes de apoyo post-penal a fin de prestar a los liberados, externados y a sus familiares, el apoyo necesario para facilitar la reinserción social, procurar su vida digna y prevenir la reincidencia, así como garantizar una atención integral y el sano desarrollo de los menores de edad de acuerdo a la Ley General de los Derechos de Niñas, Niños y Adolescentes. 
Polít. crim. Vol. 13, No 25 (Julio 2018) Art. 14, pp. 548 -

[http://www.politicacriminal.cl/Vol_13/n_25/Vol13N25A14.pdf]

\section{Bibliografía}

BINDER, Alberto, Análisis Político Criminal, Buenos Aires: Editorial Astrea, 2011, p. 151.

BRITTO RUIZ, Diana. Justicia restaurativa: Reflexiones sobre la experiencia de Colombia, Ecuador: Editorial Universidad Técnica Particular de Loja, 2010, pp. 1-142.

CARPIZO, Jorge. "Los derechos de la justicia social: Su protección procesal en México". Boletín Mexicano de Derecho Comparado, Volumen XLV, No. 135, (2012), pp. 1079-1110, p. 1080, en: http://www.scielo.org.mx/pdf/bmdc/v45n135/v45n135a6.pdf

CASTELLANOS CERECEDA, Roberto, "Comprendiendo la relación entre bienestar subjetivo, cohesión y relaciones sociales. Una aproximación al caso de México y sus entidades federativas", Circunstancia, Año XI, No. 31 (2013), p.p. 1-19, p. 8 y 10, en:

http://www.ortegaygasset.edu/admin/descargas/contenidos/Roberto_Castellanos_Cereceda.pdf

CHOYA FORÉS, Nastia. "Prácticas Restaurativas: Círculos y Conferencias". País Vasco: Justicia restaurativa: nuevas perspectivas en mediación, 2014-2015, pp. 1-50, p. 14 y 24, en: http://www.sociedadvascavictimologia.org/images/documentos/Materiales\%20postgrado/ 9\%20JUSTICIA\%20RESTAURATIVA/PRACTICAS\%20RESTAURATIVAS.pdf.

CLAASSEN, Ron en ZEHR, El pequeño libro, en: http://www.fresno.edu/pacs/

DOMINGO, Virginia. Contexto teórico-práctico de la justicia restaurativa en Europa con especial a España, Guayaquil, Ecuador: Ponencia impartida en el Congreso Internacional Ciencia Penal y Justicia Penal Restaurativa, Una mirada hacia la Justicia Restaurativa: Recuperando el derecho perdido, Criminología y justicia, (2011), pp. 70-83.

FISAS, Vinces. Cultura de paz y gestión de conflictos. Barcelona: Ed. Icaria/Antrazyt. UNESCO, 2001, pp. 1-408.

FUNDACIÓN HOGARES, IAP., "Bases para la construcción de un índice de cohesión social vecinal”, (2015), pp. 1-31, p. 10, en:

http://www.fundacionhogares.org/documentos/indice\%20de\%20coesion\%20social.pdf

GORJÓN GÓMEZ, Gabriel; GORJÓN GÓMEZ, Francisco; y Otros, Comentarios a la Ley Nacional de Mecanismos Alternativos de Solución de Controversias en Materia Penal, México D.F.: Editorial Tirant lo Blanch, 2015, p. 14.

GORJÓN GÓMEZ, Francisco Javier. "Teoría de la Impetración de la Justicia. Por la necesaria ciudadanización de la justicia y la paz", Comunitania, Revista Internacional de Trabajo Social y Ciencias Sociales, No. 10 (2015), p. 113-131, p. 115, en:

http://www.comunitania.com/numeros/numero-10/francisco-javier-gorjon-teoria-de-laimpetracion-de-la-justicia-por-la-necesaria-ciudadanizacion-de-la-justicia-y-la-paz.pdf 
SAUCEDA, Brenda; GORGÓN, Gabriel. "Justicia restaurativa, una herramienta de paz en la resolución de conflictos comunitarios. Caso Nuevo León”.

IGARTUA, I.; OLALDE, A.; y VARONA, G., en CHOYA FORÉS, Nastia. "Prácticas Restaurativas”, cit. nota núm. 2, 2014-2015, p. 9.

JIMÉNEZ-BAUTISTA, Francisco, “Conocer para comprender la violencia: origen, causas y realidad", Revista Convergencia, Revista de Ciencias Sociales, Volumen 19, No. 58, (2012), p.p. 13-52, p. 16 y 17, en: http://www.redalyc.org/pdf/105/10520680001.pdf

KELLER, Suzanne, El vecindario urbano: Una perspectiva sociológica, $2^{\text {a }}$ edición, Madrid (España): Editorial Siglo XXI, 1979.

LEDERACH, John Paul. Construyendo la paz: Reconciliación sostenible en sociedades diversas. Bilbao: Ed. Bakeaz, 1998. pp. 1-194, p. 47.

MACHICADO, J., “Apuntes jurídicos”. (2015), en:

http://jorgemachicado.blogspot.mx/2009/01/justicia-comunitaria.html

MÁRQUEZ CÁRDENAS, Álvaro E., "La doctrina social sobre la justicia restaurativa".

Prolegómenos. Derechos y Valores, Volumen XII, No. 24 (2009), p.p. 59-75, p. 59, en:

http://www.redalyc.org/pdf/876/87617269005.pdf

MURILLO TORRECILLA, F. J., \& HERNÁNDEZ CASTILLA, R., "Hacia un Concepto de Justicia Social”, REICE. Revista Iberoamericana sobre Calidad, Eficacia y Cambio en Educación, Volumen 9, No. 4 (2011), p.p. 7-23, p.18, en:

https://www.uam.es/personal_pdi/stmaria/jmurillo/arts/reice/vol9num4_art1.pdf.

ONU, Oficina de las Naciones Unidas contra la Droga y el Delito. Manual de programas de justicia restaurativa, Viena: Serie de Manuales sobre Justicia Penal, 2006, pp. 1-109, p. 6, en: https://www.unodc.org/documents/justice-and-prison-

reform/Manual_sobre_programas_de_justicia_restaurativa.pdf.

ONU, Declaración de Bangkok, Sinergias y respuestas: alianzas estratégicas en materia de prevención del delito y justicia penal, 2005, pp. 1-7, en:

https://www.unodc.org/pdf/crime/congress11/BangkokDeclaration_sp.pdf

ROMERA I. RUEDA, Raúl. Guerra, posguerra y paz: Pautas para el análisis y la intervención en contextos posbélicos o post-acuerdo, Barcelona: Editorial Icaria, 2003, pp. 1-198.

SAMPEDRO ARRUBLA, Julio Andrés, “¿Qué es y para qué sirve la Justicia Restaurativa?”, Revista Derecho Penal, núm. 12 (2005), pp. 53-85, en: http://legal.legis.com.co/document?obra=rpenal\&document=rpenal_7680752a8057404ce $0430 \mathrm{a} 010151404 \mathrm{c}$

VALDEZ, C., “Análisis jurídico y político”, Revista Equidad, (2014), en: http://revistaequidad.com/?p=21291 
Polít. crim. Vol. 13, No 25 (Julio 2018) Art. 14, pp. 548 -

[http://www.politicacriminal.cl/Vol_13/n_25/Vol13N25A14.pdf]

VINYAMATA CAMP, Eduard, "Conflictología”, Revista de Paz y Conflictos, vol. 8, no 1 (2015), pp. 9-24, p. 17, en: http://revistaseug.ugr.es/index.php/revpaz/article/view/2717/3176

ZEHR, Howard. El pequeño libro de la justicia restaurativa. Pennsylvania: Good Books, 2007, pp. 1-96, en:

http://www.icbf.gov.co/portal/page/portal/PortalICBF/bienestar/proteccion/responsabilida d-penal/justicia-restaurativa/Howard\%20Zher\%20-

$\% 20$ El\%20pequen\%CC\%83o\%20Libro\%20de\%20la\%20Justicia\%20Restaurativa.pdf 